\title{
Challenges for health in the Anthropocene epoch
}

\author{
A new series and a call for papers
}

\author{
Andy Haines professor of environmental change and public health ${ }^{1}$, Pauline Scheelbeek assistant \\ professor in nutritional and environmental epidemiology ${ }^{1}$, Kamran Abbasi executive editor ${ }^{2}$
}

'London School of Hygiene and Tropical Medicine, London, UK; ${ }^{2}$ The BMJ

Humanity experienced unprecedented but unequal progress over the past century. Globally, the successful escape of many millions from poverty was accompanied by considerable improvements in living conditions, such as access to water and sanitation, improved hygiene, and better housing. ${ }^{1}$ Access to effective healthcare resulted in improvements in both communicable and non-communicable disease prevention and treatment, ${ }^{2}$ leading to advances in health, including a rapid increase in global life expectancy and a steep decline in under 5 mortality. ${ }^{3}$

Increased prosperity and better human health come at a cost, however. Economic and population growth increase demand for food, energy, and natural resources. ${ }^{4}$ These demands are met in an unsustainable way that includes an over-reliance on fossil fuels. ${ }^{4}$ Biodiversity is being lost at a rate 100 times greater than background rates in pre-human times, because of, for example, deforestation, urbanisation, and climate change. ${ }^{5}$ The oceans are acidifying from dissolved carbon dioxide, while additional threats to marine ecosystems are posed by plastic and other pollution, and overfishing. ${ }^{6}$

The multiplicity of changes in the Earth's natural systems is captured in the term "Anthropocene epoch," originally coined by Paul Crutzen, to describe our current age. ${ }^{7}$ The Anthropocene is characterised by the dominance of humans over the global environment and replaces the Holocene epoch, a period of relative climatic stability lasting around 11500 years, during which humanity moved from being hunter-gatherers to agriculturalists to today's predominantly urban population.

Humanity can safely flourish within nine planetary boundaries regulating the interactions between oceans, land, atmosphere, and life, and thus the stability of the Earth system as a whole. ${ }^{4}$ Four of these boundaries have been crossed and a number are now under imminent threat, increasing risks to human health. ${ }^{4}$ For example, rising levels of greenhouse gas and short lived climate pollutant emissions worldwide have increased average global temperature ${ }^{8}$ to approximately $1{ }^{\circ} \mathrm{C}$ above pre-industrial levels. ${ }^{9}$ Current commitments to emission reductions under the Paris Climate Agreement would result in a temperature increase of over $3^{\circ} \mathrm{C}$ by the end of the century, posing severe challenges for populations worldwide, particularly those with limited capacity to adapt. ${ }^{10}$

\section{Health threats}

Increasing temperatures from climate change have major implications for mortality rates and labour productivity, particularly in tropical and sub-tropical regions. ${ }^{112}$ Effects mediated through disturbances in natural systems include changes in the transmission of vectorborne, waterborne, and foodborne diseases, together with serious threats to food security and nutritional quality of food. ${ }^{1314}$ Other effects will be mediated through socioeconomic mechanisms, such as increasing poverty. Those populations which have contributed least to environmental change are often most vulnerable to its effects, further widening already unacceptable inequities. ${ }^{15}$

Safeguarding human health means staying in the "safe operating space" within planetary boundaries. This realisation gave birth to a new interdisciplinary scientific field, planetary health, which conceptualises that human health and natural systems are interdependent. ${ }^{16}$ It underscores the urgency of protecting the Earth's natural "life support" systems when developing strategies for population health.

Potential solutions to these threats must increase the resilience of populations to any changes that cannot be prevented, ${ }^{17}$ as well as capitalising on transformative policies, interventions, and technologies that reduce our environmental footprint, while protecting and promoting health. ${ }^{18}$ Promising strategies to help populations adapt include early warning systems for extreme heat, floods, and infectious disease outbreaks, ${ }^{19}$ and provision of water and sanitation systems capable of withstanding extreme events. ${ }^{20}$ Natural solutions, such as protecting mangroves or wetlands, help reduce risks of coastal flooding, ${ }^{21}$ and exposure to green space improves mental health. ${ }^{22}$

Transformative, sustainable policies in sectors such as energy, transport, housing, industry, food, and agriculture may yield major health benefits from reduced air pollution, increased physical activity, and improved diets. ${ }^{23}$ Careful planning can minimise unintended adverse consequences, such as worsening inequalities. Recent disturbances in France after a proposed rise 
in fuel taxes emphasise the need to engage the public in potential solutions and anticipate barriers to change. Societies must move towards a circular economy that prioritises recycling, reuse, and shared ownership, and minimises waste-with appropriate safeguards to reduce risks from exposure to hazardous chemicals. ${ }^{24}$ Health professionals have a vital part to play in reducing the environmental impact of health services; increasing resilience to environmental change; supporting healthy, sustainable behaviours; and advocating for policies to protect planetary health. ${ }^{25}$

\section{Call for submissions}

The $B M J$ is planning a special series on planetary health and the practical transformations needed to improve human health and protect our essential natural systems. Our knowledge of the challenges and opportunities in the Anthropocene epoch is still evolving and we aim to stimulate debate, advance understanding, and share experience. We call for manuscripts that assess threats to planetary health and present evidence for relevant policies and interventions -including ideas for feature articles or multimedia-illustrating what can be achieved at local level.

We invite submissions for consideration that describe the effects of environmental change on health or factors increasing vulnerability to such changes; strategies to promote resilience to environmental change, including evaluation of specific approaches to adaptation; effectiveness of more sustainable interventions and policies to improve health, including low carbon and circular economy approaches; and lessons learnt from successes and failures at local or regional level.

We hope this special series will raise awareness of the threats to humanity and natural systems in the Anthropocene epoch, but more importantly will inspire creative and far sighted responses to our era's pressing challenges.

We have read and understood BMJ policy on declaration of interests and declare the following interests: None.

1 Deaton A. The great escape: health, wealth, and the origins of inequality. Princeton University Press, 2013.

2 Pinker S. Enlightenment now: the case for reason, science, humanism, and progress. Penguin, 2018.

3 Roser M. Our world in data. https://ourworldindata.org.

4 Steffen W, Richardson K, Rockström J, et al. Planetary boundaries: guiding human development on a changing planet. Science 2015;347:125985510.1126/science.1259855. De Vos JM, Joppa LN, Gittleman JL, Stephens PR, Pimm SL. Estimating the normal background rate of species extinction. Conserv Biol 2015;29:452-6210.1111/cobi.12380.
6 Jackson JB. The future of the oceans past. Philos Trans $R$ Soc Lond B Biol Sci 2010;365:3765-7810.1098/rstb.2010.0278.

7 Crutzen PJ. Geology of mankind. Nature 2002;415:2310.1038/415023a.

8 Rogelj J, Schaeffer M, Meinshausen M, et al. Disentangling the effects of $\mathrm{CO} 2$ and short-lived climate forcer mitigation. Proc Natl Acad Sci USA 2014;111:16325-3010.1073/pnas.1415631111.

9 National Aeronautics and Space Administration, Goddard Institute for Space Studies. GISS surface temperature analysis (GISTEMP). https://data.giss.nasa.gov/gistemp.

10 Tollefson J. IPCC says limiting global warming to $1.5^{\circ} \mathrm{C}$ will require drastic action. Nature 2018;562:172-310.1038/d41586-018-06876-2.

11 Gasparrini A, Guo Y, Sera F, et al. Projections of temperature-related excess mortality under climate change scenarios. Lancet Planet Health. 2017;1:e360-710.1016/S2542-5196(17)30156-0.

12 Andrews O, Le Quéré C, Kjellstrom T, Lemke B, Haines A. Implications for workability and survivability in populations exposed to extreme heat under climate change: a modelling study. Lancet Planet Health. 2018;2:e540-710.1016/S2542-5196(18)30240-7.

13 Scheelbeek PF, Bird FA, Tuomisto HL, et al. Effect of environmental changes on vegetable and legume yields and nutritional quality. Proc Natl Acad Sci 2018:201800442.

14 Springmann M, Mason-D'Croz D, Robinson S, et al. Global and regional health effects of future food production under climate change: a modelling study. Lancet 2016:387:1937-4610.1016/S0140-6736(15)01156-3.

15 Klinsky S, Roberts T, Huq S, et al. Why equity is fundamental in climate change policy research. Glob Environ Change 2017;44:170-310.1016/j.gloenvcha.2016.08.002.

16 Whitmee S, Haines A, Beyrer C, et al. Safeguarding human health in the Anthropocene epoch: report of the Rockefeller Foundation-Lancet Commission on planetary health. Lancet 2015:386:1973-202810.1016/S0140-6736(15)60901-1.

17 Cinner JE, Adger WN, Allison EH, et al. Building adaptive capacity to climate change in tropical coastal communities. Nature Climate Change 2018;8:117-23.

18 Watts N, Amann M, Ayeb-Karlsson S, et al. The Lancet Countdown on health and climate change: from 25 years of inaction to a global transformation for public health. Lancet 2018;391:581-63010.1016/S0140-6736(17)32464-9.

19 Ebi KL, Schmier JK. A stitch in time: improving public health early warning systems for extreme weather events. Epidemiol Rev 2005;27:115-2110.1093/epirev/mxi006.

20 Wu X, Lu Y, Zhou S, Chen L, Xu B. Impact of climate change on human infectious diseases: empirical evidence and human adaptation. Environ Int 2016;86:14-2310.1016/j.envint.2015.09.007.

21 Spalding MD, Mclvor AL, Beck MW, et al. Coastal ecosystems: a critical element of risk reduction. Conserv Lett 2014;7:293-30110.1111/conl.12074.

22 Gascon M, Triguero-Mas M, Martínez D, et al. Mental health benefits of long-term exposure to residential green and blue spaces: a systematic review. Int J Environ Res Public Health 2015;12:4354-7910.3390/ijerph120404354.

23 Haines A, McMichael AJ, Smith KR, et al. Public health benefits of strategies to reduce greenhouse-gas emissions: overview and implications for policy makers. Lancet 2009;374:2104-1410.1016/S0140-6736(09)61759-1.

24 World Health Organization Regional Office for Europe. Circular economy and health opportunities and risks. 2018. www.euro.who.int/en/publications/abstracts/circulareconomy-and-health-opportunities-and-risks-2018.

25 Xie E, de Barros EF, Abelsohn A, Stein AT, Haines A. Challenges and opportunities in planetary health for primary care providers. Lancet Planet Health. 2018;2:e185-710.1016/S2542-5196(18)30055-X

Published by the BMJ Publishing Group Limited. For permission to use (where not already granted under a licence) please go to http://group.bmj.com/group/rights-licensing/ permissions 